\title{
Detecting a decline in whale shark Rhincodon typus sightings in the Andaman Sea, Thailand, using ecotourist operator-collected data
}

\author{
Michelle M. Theberge and Philip Dearden
}

\begin{abstract}
In this paper, we analyse long-term whale shark Rhincodon typus sightings collected by ecotourist operators and evaluate the validity of conclusions drawn from the data for scientific and conservation purposes. To date information about the basic ecology and movements of whale sharks is sparse, and only recently has the species received global conservation attention. A dive company in Phuket, Thailand, documented whale shark sightings in the Andaman Sea for 10 years along $300 \mathrm{~km}$ of coastline. Whale shark sightings, corrected for effort, dropped by $96 \%$ between 1998 and 2001. Combining the
\end{abstract}

seasons from 1992 to 1998, the number of whale shark sightings increased significantly from October to May. The sizes of sharks observed suggest that the majority were juveniles. We discuss the limitations of using ecotourist operators as non-specialist volunteers for data collection but conclude that their use can be beneficial for long-term, broad geographic studies such as this.

Keywords Ecotourism, endangered species, marine conservation, monitoring, Rhincodon typus, volunteers, whale shark.

\section{Introduction}

The whale shark Rhincodon typus is a long-lived and highly transitory species that is logistically and financially difficult to study. Information about the basic ecology and movements of the species is sparse (Taylor, 1996; Gunn et al., 1999; Eckert \& Stewart, 2001; Wilson et al., 2001; Eckert et al., 2002). Their distribution spans all tropical and most warm temperate waters but they are observed seasonally in only in a few regions of the world.

Concern over global whale shark populations has increased recently because of the unknown effect of past, largely unregulated, harvest. Until 2000 the IUCN categorized the whale shark as Data Deficient but in 2002 the category was changed to Vulnerable because of a suspected $20 \%$ decline and a further projected reduction of $20 \%$ over the next 10 years (IUCN, 2006). That same year, whale sharks became legally protected under Appendix II of CITES (CITES, 2003). Whale sharks are now protected in Australia, Philippines, USA, Maldives, Malaysia, Honduras and India (Fowler

\footnotetext{
Michelle M. Theberge ${ }^{\star}$ (Corresponding author) and Philip Dearden Marine Protected Areas Research Group, Department of Geography, PO Box 3050, University of Victoria, Victoria, British Columbia, Canada V8W 3P5. E-mail mich_theberge@yahoo.com

${ }^{*}$ Current address: 4370 Fleetwood Road, Duncan, British Columbia, Canada V9L 6N3.

Received 4 January 2005. Revision requested 20 April 2005 Accepted 19 September 2005
}

\& Cavanagh, 2001), and have been included in Appendix II of the Convention for Migratory Species.

Even with the whale sharks' inclusion on conservation lists, more information regarding life history and movements is necessary to understand the impacts of possible overexploitation. The species is vulnerable to exploitation because of directed fisheries, its high value in international trade, its highly migratory nature and its low abundance (IUCN, 2006). Geographically broad data on whale shark populations that are collected systematically and reliably are urgently needed.

Whale sharks have been observed off the west coast of Thailand by the members of the Phuket scuba diving industry since 1990. Many companies offer dive excursions that specifically target whale sharks (Bennett, 2002) and in the 1998-1999 season anecdotal observations by the industry suggested that whale shark numbers in the region had been declining. However, Fantasea Divers, a local dive charter company, was the only company from Phuket that kept detailed records of whale sharks and other large marine fauna along $300 \mathrm{~km}$ of coastline.

Recently, interest has grown within the conservation community for using such non-specialist volunteers in data collection (Dartwell \& Dulvy, 1996; Greenberg \& Droege, 1999; Foster-Smith \& Evans, 2003), especially those involved with ecotourist activities (Galley \& Clifton, 2004) and operations (Colman, 1997). Nonspecialist volunteers refers to non-scientists who participate in research studies, and who vary in age, experience and training (Dartwell \& Dulvy, 1996). In 
this paper, we examine long-term data collected by volunteer ecotourist operators for trends in whale shark movements and numbers in the Andaman Sea, and evaluate the validity of the conclusions drawn from the data for scientific and conservation purposes.

\section{Study area}

Information was collected at scuba diving sites in the Andaman Sea off the west coast of Thailand between $7^{\circ} 10^{\prime} 00^{\prime \prime}$ and $9^{\circ} 55^{\prime} 00^{\prime \prime} \mathrm{N}$. The study area extended approximately $300 \mathrm{~km}$ along most of the Thailand coast from near the Malaysian border to the southernmost islands of the Mergui Archipelago, Myanmar (Fig. 1). The four general geographic regions within the area are referred to as the North, Mid, Similans and South.

\section{Methods}

Fantasea Divers is one of the oldest of over 80 scuba diving companies operating out of Phuket. It has been in operation since 1979 and caters to underwater naturalists and photographers during the non-monsoon months between October and May. It is the only dive company in the region that has kept consistent logbooks documenting sightings of whale sharks and other marine fauna by three of its cruise leaders and longterm employees. Whale Shark Sighting Logbooks were kept for 10 seasons (October to May) from 1991-1992 to 2000-2001. These logbooks contain the number of whale sharks seen, the sex, total estimated length, and descriptions (i.e. scars, markings and notches). An individual whale shark seen underwater by the staff more than once in a day at a dive site was recorded only once.

Effort logbooks document the number of trips per season and number of dives per trip. Information on effort, however, was unavailable for four seasons (1991-1992, 1998-1999, 1999-2000 and 2000-2001). Over the latter 3 seasons only the number of trips was available. Therefore, the annual number of dives for these seasons was estimated from the average number of dives per trip between 1992-1993 and 1997-1998 (20.7) multiplied by the number of trips. Data regarding weather and sea conditions during the dives were not recorded consistently enough for use in this study.

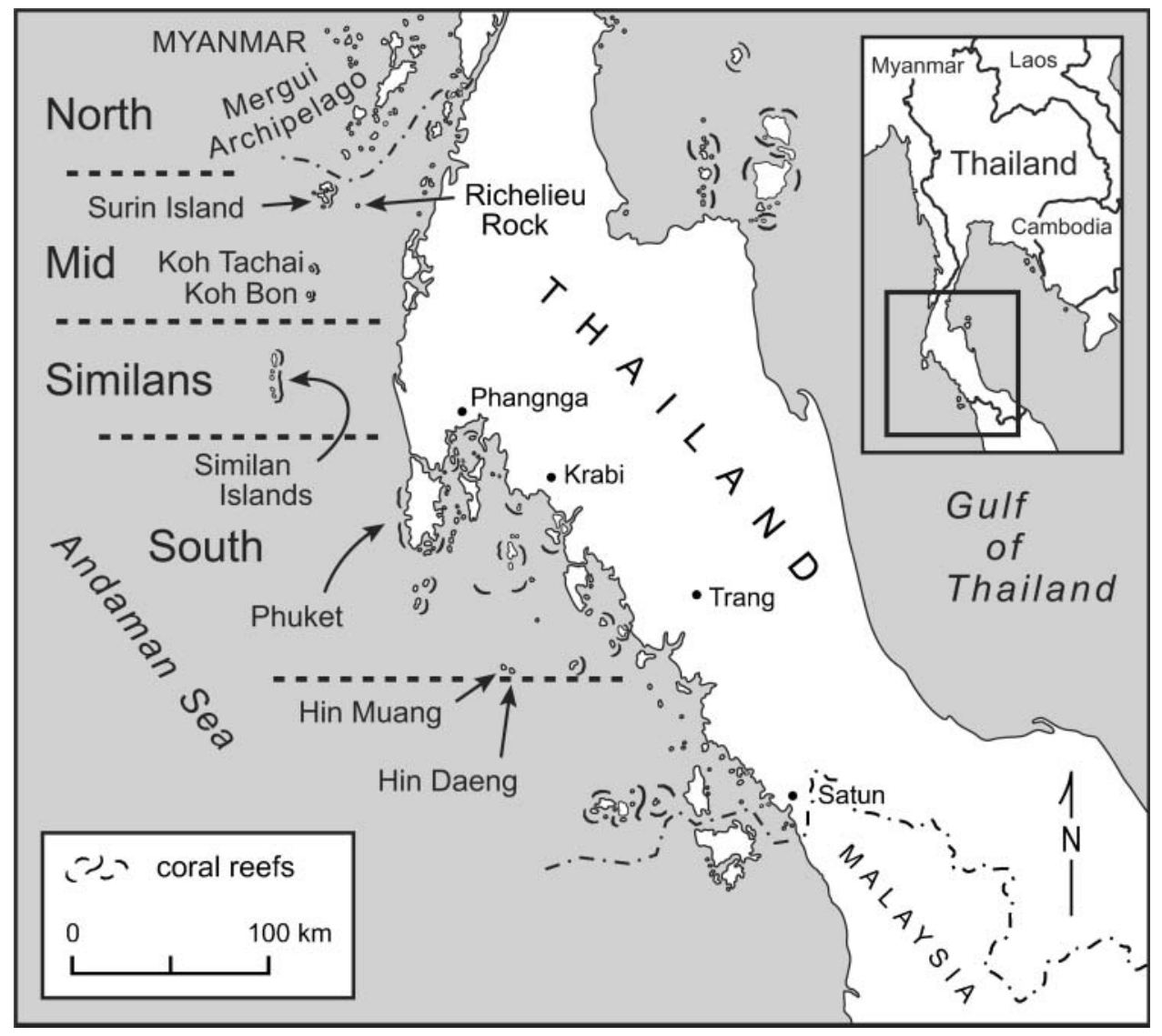

Fig. 1 The locations and dive sites where whale sharks were recorded between the 1991-1992 and 2000-2001 dive seasons. The rectangle on the inset shows the location of the main map in Thailand. 
Two indices representing whale sharks per unit effort (WSE) were created to indicate the relative number of whale sharks seen per trip and per dive. These indices were calculated by dividing the number of whale sharks sighted by the number of trips or dives. The same calculations were computed for the four geographic regions. In addition, the average WSE per month (October to May) over 9 seasons was compiled. Regression analyses were used to examine the relationships between WSE and month, and WSE per season.

Records of seasonal sightings were examined to discern and remove repeat sightings of the same whale shark. Descriptions were available for approximately half of the observations. The animal was considered a distinct individual whale shark if it had unmistakably prominent features on the dorsal fin or the tail (e.g. missing the dorsal fin or the top of tail lobe), or if the visual description included identifiable features on all of the right, left and dorsal views of the animal. Fresh wounds were not considered as adequate visual descriptions because the same shark might have been sighted previously before the wound was present. Size was considered only if the size difference between two sharks similar in appearance was greater than $5 \mathrm{~m}$. If there was any ambiguity in the visual description or uncertainty in identity, the animal was not counted as a distinct individual.

\section{Results}

Between 1992 and 2001 Fantasea Divers recorded 253 whale shark observations over a total of 218 trips and c. 4,515 dives (Table 1). Numbers of sightings ranged from 51 during the 1995-1996 season to 0 during 1999 2000. On average 42 whale sharks sightings were made per season between 1991-1992 and 1997-1998, dropping to 1.3 sightings per season between 1998-1999 and 2000-2001.

Ninety-eight observations included visual descriptions, and from these a minimum count of distinct individuals was generated for each season (Table 1). Hence, the true number of whale sharks generating the observations each season lies between the total number of whale sharks sighted and the minimum count of distinct individuals.

The WSE per dive for all animals sighted dropped significantly over 9 seasons $(r=0.78, \mathrm{P}<0.01)$. All seasons combined, the average WSE per dive between October to May rose significantly $(r=0.591, \mathrm{P}<0.01)$, and there were comparable trends for WSE per trip (Fig. 2). The average WSE per dive was 0.77 between the 1992-1993 to 1997-1998 seasons, and 0.03 between the 1998-1999 to 2000-2001 seasons, representing a drop of $96 \%$. The highest WSE per dive was 1.02 in 1995-1996 and lowest was 0 in 1999-2000 (Table 1).

Within the four geographic regions, Fantasea Divers routinely dived at 37 sites, sighting whale sharks at $41 \%$ of these. The highest WSE per dive was recorded in the Mid Region (0.22) followed by the South (0.21), the Similans (0.02) and the North (0.01). The dive company spent the majority of their time in the Mid Region (40\%), followed by the Similans (30\%), North (22\%) and South $(8 \%)$. Sighting effort was only available, however, in the North and South Regions after the 1995-1996 seasons.

The sex of each whale shark was recorded for only 159 sightings (63\%) and consisted of 84 males and 75 females. For the minimum count of distinct individuals there were 28 males and 22 females. Total length was estimated for $99 \%$ of all observations. The majority (62\%) were between 4 and $5 \mathrm{~m}$, and only $1.3 \%>8 \mathrm{~m}$. Fourteen percent of individuals were $3-4 \mathrm{~m}$, and $21 \% 6-7 \mathrm{~m}$.

Table 1 The number of whale shark sightings and sightings including visual descriptions (i.e. scars, markings, notches), the minimum count of distinct whale sharks (i.e. different individuals), sighting effort, and the whale shark per unit effort indices representing whale shark sightings per number of trips and dives for each season.

\begin{tabular}{|c|c|c|c|c|c|c|c|}
\hline \multirow[b]{2}{*}{ Season } & \multirow{2}{*}{$\begin{array}{l}\text { Whale } \\
\text { shark } \\
\text { sightings }\end{array}$} & \multirow{2}{*}{$\begin{array}{l}\text { No. of sightings } \\
\text { with visual } \\
\text { descriptions }\end{array}$} & \multirow{2}{*}{$\begin{array}{l}\text { Minimum count } \\
\text { of distinct } \\
\text { individuals }\end{array}$} & \multicolumn{2}{|l|}{ Effort } & \multicolumn{2}{|c|}{ Whale shark per unit effort } \\
\hline & & & & No. of trips & No. of dives & Per trip & Per dive $(x 10)$ \\
\hline 1991-1992 & 45 & unknown & unknown & unknown & unknown & unknown & unknown \\
\hline 1992-1993 & 41 & 6 & 6 & 26 & 462 & 1.58 & 0.89 \\
\hline 1993-1994 & 28 & 14 & 10 & 28 & 498 & 1.00 & 0.56 \\
\hline 1994-1995 & 36 & 16 & 7 & 27 & 482 & 1.33 & 0.75 \\
\hline 1995-1996 & 51 & 23 & 8 & 27 & 498 & 1.89 & 1.02 \\
\hline 1996-1997 & 43 & 20 & 10 & 24 & 615 & 1.79 & 0.70 \\
\hline 1997-1998 & 50 & 17 & 9 & 25 & 697 & 2.00 & 0.72 \\
\hline 1998-1999 & 2 & 1 & 1 & 25 & $517.80^{*}$ & 0.08 & $0.04^{*}$ \\
\hline 1999-2000 & 0 & 0 & 0 & 20 & $414.24^{*}$ & 0.00 & 0.00 \\
\hline 2000-2001 & 2 & 1 & 1 & 16 & $331.39 *$ & 0.13 & $0.06^{*}$ \\
\hline
\end{tabular}

*estimate 


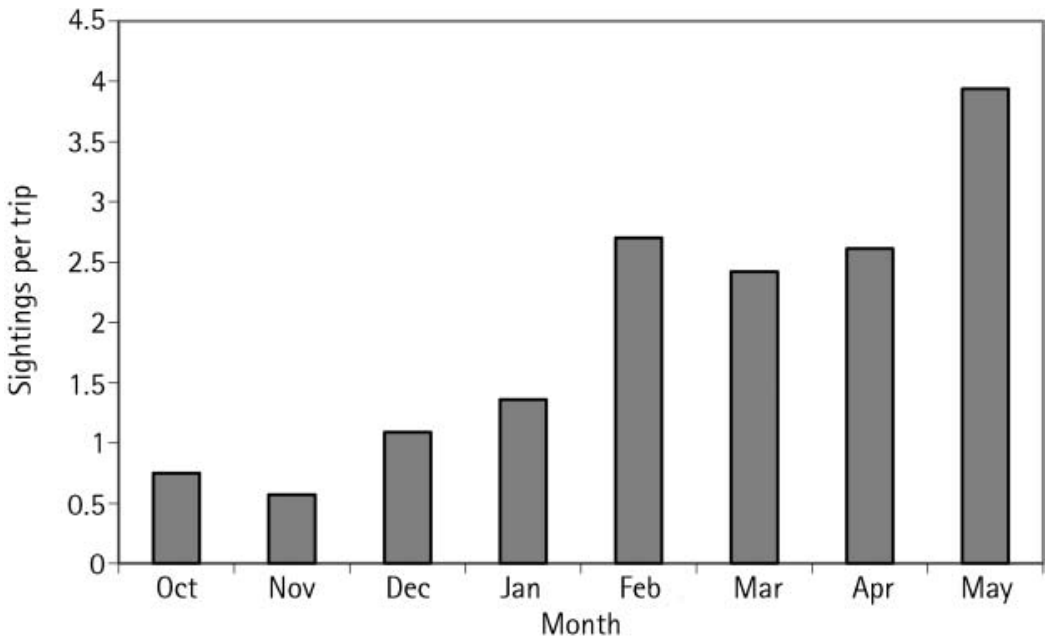

Fig. 2 The monthly average whale shark sightings per trip from October to May for nine seasons combined (1991-1992 to 2000-2001).

\section{Discussion}

\section{Whale shark decline}

The data show a dramatic decrease in whale shark sightings, dropping in relation to effort by $96 \%$ from 1991-1992 to 2000-2001. After our study was completed Fantasea Divers continued to collect sightings, but not dive effort, and in the 2001-2002 and 2002-2003 seasons, the total whale shark observations were 10 and 3, respectively. Although members of the Phuket diving community, rather than trained scientists, reported such a decline, these are the only data available. Currently, we know of no other study that shows trends in whale shark numbers in a broad geographical area over a long period of time. This study is an example of monitoring initiated when the conservation status about the species was unknown, but was later useful in documenting a possible change in population status.

Between October and May whale shark sightings increased significantly. Our results are consistent with Prater's (1942) idea that during these months whale shark movements correspond with increasing plankton production in the Andaman Sea and intensifying surface currents that run along Thailand's west coast and across the Bay of Bengal (Wyrtki, 1961). Consequently, the overall decline in whale shark sightings observed in this study could be due to yearly variability of these surface currents and of plankton production in the region.

The presence of whale sharks may also be correlated with global oceanographic events such as El Nĩno and La Nĩna, which can influence the strength of currents running along the west coast of Thailand. Wilson et al. (2001) suggested that whale sharks in the Indian Ocean travel with the currents associated with El Nĩno in combination with other oceanographic fluctuations. During the period of this study strong El Nĩno and La Nĩna events occurred in 1997-1998 and 1998-1999, respectively. The highest number of whale sharks in this study was observed during the El Nĩno season. Sightings of whale sharks in relation to dive effort made in the season before the El Nĩno were 15.6\% lower and after (La Nĩna) were $96.3 \%$ lower.

The decrease in numbers could also be due to harvesting. Whale shark fisheries for fins and meat expanded during the 1990s stimulating an increase in harvesting effort in India. In 1999 anecdotal reports indicated that $>1,000$ whale sharks were killed in only 3 villages off the west coast of India where local villagers reported declines in total whale shark catch rates of $50-75 \%$ (Shark Research Institute, 2004). It is possible that whale sharks off the east coast of India are the same individuals that travel through the Andaman Sea and the Bay of Bengal (Prater, 1942). More information regarding whale shark travel and migration routes needs to be gathered, however, before clear conclusions can be drawn.

Ecotourists diving with sharks can have negative impacts on certain species but these impacts are largely the result of intrusive feeding techniques, such as chumming (Burgess, 1998). Although diving with whale sharks does not include feeding to attract them, it is presently unclear whether pressures from tourism generate short or long-term detrimental impacts on groups of whale sharks or individuals. Evidence of impacts is difficult to obtain without knowledge of the natural variability in whale shark abundance and distribution (Colman, 1997).

We found no evidence of sexual segregation. As general information regarding whale shark life history is lacking, it is not possible to ascertain if sexual segregation, either geographical or behavioural, typically occurs (Colman, 1997). At Ningaloo Reef, Australia, however, Taylor (1996) observed that the majority of whale sharks were immature males. 
The sizes of whale sharks observed in this study suggest that the majority were juveniles, as only $1.3 \%$ were $>8 \mathrm{~m}$, and $62 \%$ were estimated at $<5 \mathrm{~m}$. Taylor (1996) speculated that whale sharks may not reach sexual maturity until they are $>30$ years of age and $>9 \mathrm{~m}$ in length (Colman, 1997).

\section{Evaluation of non-specialist collected data}

The data collected by non-specialist volunteer ecotourist operators in this study represent the only quantitative record of whale sharks off the west coast of Thailand. While the data collection was not pre-designed for scientific analysis, the data were recorded consistently. Similar information collected without a link to commercial ecotourism, and taking place over 10 8-month periods, and encompassing $300 \mathrm{~km}$ of coastline would have been financially and logistically difficult to obtain.

While the use of non-specialist volunteers has obvious advantages, the data collected has been criticized for lacking reliability and precision (Dartwell \& Dulvy, 1996). Although many researchers have used nonspecialist volunteers in their research, few have actually validated their effectiveness or compared their data with data collected by scientists (Newman et al., 2003). Some studies that made such comparisons reported no difference between scientists and trained volunteers when collecting data such as terrestrial wildlife observations (Newman et al., 2003) or stream samples (Fore et al., 2001). Other types of data collection, however, can be sufficiently technical and difficult for volunteers (Newman et al., 2003). Below we list several limitations that occurred with our non-specialist volunteer collected data and suggest ways they were, or could be, resolved.

Gaps in the database Dive effort was missing during certain seasons, requiring the calculation of derived values (see Methods). In addition, visual descriptions were given for only half of the observations making it difficult to determine which observations were repeat sightings. Consequently, a minimum count of distinctly identifiable sharks was obtained from the visual descriptions, allowing inferences to be made regarding the true number of whale sharks per year (Table 1). The sample size for sex was limited as only $63 \%$ of individual whale sharks had been recorded as male or female.

Lack of systematic sampling The dive company spent less time in the North and South Regions, thus weakening the ability to draw conclusions about comparative abundance among different geographic locations to determine if coastal migration was taking place.
Subjective data Estimations of length were subjective. In future, trial tests could be conducted regularly with large objects of known length (e.g. various boat hulls) to help evaluate and calibrate the observers' skill. Also, recording the approximate distance of the observer from the animal would have increased the confidence in size estimation.

Miscounting Although whale sharks themselves are unmistakable, distinguishing between individuals is difficult. The company's logbooks included columns for documenting visual descriptions to avoid double counting. However, photographic records of the animals corresponding to the logbook would have been more useful for positive identifications.

\section{Conclusions}

This study, using data collected by non-specialist volunteer ecotourist operators, has shown a marked decline in the number of whale shark sightings per unit effort and has provided insight into possible travel patterns and demographics in the Andaman Sea. We have evaluated the strengths and weaknesses of the data against a set of general concerns, and conclude that the data are sufficient for detecting trends. Clearly, there should be concern over the population status of whale sharks in the Andaman Sea. Until further studies are conducted, precautionary measures for whale shark protection, such as monitoring ecotourism activities, implementing stronger conservation legislation and increasing fines for illegal fishing, should be taken within Thailand's waters as well as in international waters.

\section{Acknowledgements}

We would like to thank the staff at Fantasea Divers (Mark Strickland, Suzanne Foreman, Hans Tibboel and Jerone Deknatel) for providing data as well as logistical support during this study. We also thank the Thai Marine Parks Division as well as the Department of Forestry at Kasetsart University for their assistance. We are grateful for financial support from the Project AWARE Foundation, the Centre for Asian Pacific Studies at the University of Victoria, Canada, and the Social Science and Humanities Research Council of Canada. We also thank three anonymous reviewers for their comments.

\section{References}

Bennett, M. (2002) Dive Tourism in Phuket, Thailand: Pursung Sustainability. MSc thesis, University of Victoria, BC, Canada. Burgess, G.H. (1998) Diving with Elasmobranchs: A Call for Restraint. Newsletter of the IUCN Shark Specialist Group, No. 11, Berkshire, UK. 
CITES (2003) Checklist of CITES Species: A Reference to the Appendices to the Convention on International Trade in Endangered Species of Wild Fauna and Flora. UNEP World Conservation Monitoring Centre, Cambridge, UK [http:/ / www.cites.org, accessed 15 October 2003].

Colman, J. (1997) Whale Shark Interaction Management with Particular Reference to Ningaloo Marine Park. Wildlife Management Program, Department of Conservation and Land Management, Freemantle, Australia.

Dartwell, W.R.T. \& Dulvy, N.K. (1996) An evaluation of the suitability of non-specialist volunteer researchers for coral reef fish surveys. Mafia Island, Tanzania - A case study. Biological Conservation, 18, 259-271.

Eckert, S.A., Dollar, L.L., Kooyman, G.L., Perrin, W. \& Abdul Rahman, R. (2002) Movements of whale shark (Rhincodon typus) in South-east Asian waters as determined by satellite telemetry. Journal of Zoology, 257, 111-115.

Eckert, S.A. \& Stewart, B.S. (2001) Telemetry and satellite tracking of whale sharks (Rhincodon typus) in the Sea of Cortez, Mexico, and the north Pacific Ocean. Environmental Biology of Fishes, 60, 299-308.

Fore, L.S., Paulsen, K. \& O'Laughlin, K. (2001) Assessing the performance of volunteers in monitoring streams. Freshwater Biology, 46, 106-123.

Foster-Smith, J. \& Evans, S.M. (2003) The value of marine ecological data collected by volunteers. Biological Conservation, 113, 199-213.

Fowler, S. \& Cavanagh, R. (2001) CITES update. Shark News, 13, 9.

Galley, G. \& Clifton, J. (2004) The motivational and demographic characteristics of research ecotourists: Operation Wallacea volunteers in southeast Sulawesi, Indonesia. Journal of Ecotourism, 3, 69-81.

Greenberg, R. \& Droege, S. (1999) On the decline of the rusty blackbird and the use of ornithological literature to document long-term population trends. Conservation Biology, 13, 553-559.

Gunn, J.S., Stevens, J.D., Davis, T.L.O. \& Norman, B.M. (1999) Observations on the short term movements and behaviour of whale sharks (Rhincodon typus) at Ningaloo Reef, Western Australia. Marine Biology, 135, 553-559.
IUCN (2006) 2006 IUCN Red List of Threatened Species. IUCN, Gland, Switzerland [http://www.redlist.org, accessed 13 June 2006].

Newman, C., Buesching, C.D. \& Macdonald, D.W. (2003) Validating mammal monitoring methods and assessing the performance of volunteers in wildlife conservation - "Sed quis custodiet ipsos custodies?" Biological Conservation, 113, 189-197.

Prater, S.H. (1942) The whale shark (Rhineodon typus) (Smith) in Indian coastal waters. Journal of the Bombay Natural History Society, 42, 255-279.

Shark Research Institute (2004) Whale Sharks. http://www.sharks.org/whale_shark/index.htm [accessed July 2004].

Taylor, J.G. (1996) Seasonal occurrence, distribution and movements of the whale shark (Rhincodon typus) at Ningaloo Reef, Western Australia. Marine Freshwater Research, 47, 637-642.

Wilson, S.G., Taylor, J.G. \& Pearce, A.F. (2001) The seasonal aggregation of whale sharks at Ningaloo Reef, Western Australia: currents, migrations and the El Nino / Southern Oscillation. Environmental Biology of Fishes, 61, 1-11.

Wyrtki, K. (1961) Scientific Results of Marine Investigations of the South China Sea and Gulf of Thailand 1959-1961: Physical Oceanography of South East Asian Waters. Scripps Institute of Oceanography, University of California, La Jolla, USA.

\section{Biographical sketches}

Michelle Theberge's research interests are in biodiversity and conservation related initiatives in Canada, South-east Asia and the Caribbean. She currently works with protected area management in Canadian National Parks.

Philip Dearden leads the Marine Protected Areas Research Group at the University of Victoria, with marine conservation projects in Thailand, Sri Lanka and Canada. His main research interests are in protected area designation and management, marine park planning and ecotourism. 